\title{
Fotografía Latinoamericana Contemporánea: imaginarios, archivos y memoria. Una aproximación a la obra de Milagros de la Torre
}

\section{Artículo de investigación}

\section{Leticia Rigat}

Universidad Nacional de Rosario - CONICET, Argentina letirigat@hotmail.com

Recibido el: $26 / 05 / 2020$

Aceptado el: 28/09/2020

Cómo citar este artículo: Rigat, L. (2021). Fotografía Latinoamericana Contemporánea: imaginarios, archivos y memoria. Una aproximación a la obra de Milagros De la Torre. Calle 14: revista de investigación en el campo del arte. 16(30), pp. 220-235.

https://doi.org/10.14483/21450706.18297

\section{(a) (1)}

https://creativecommons.org/licenses/by/4.0/deed.es 


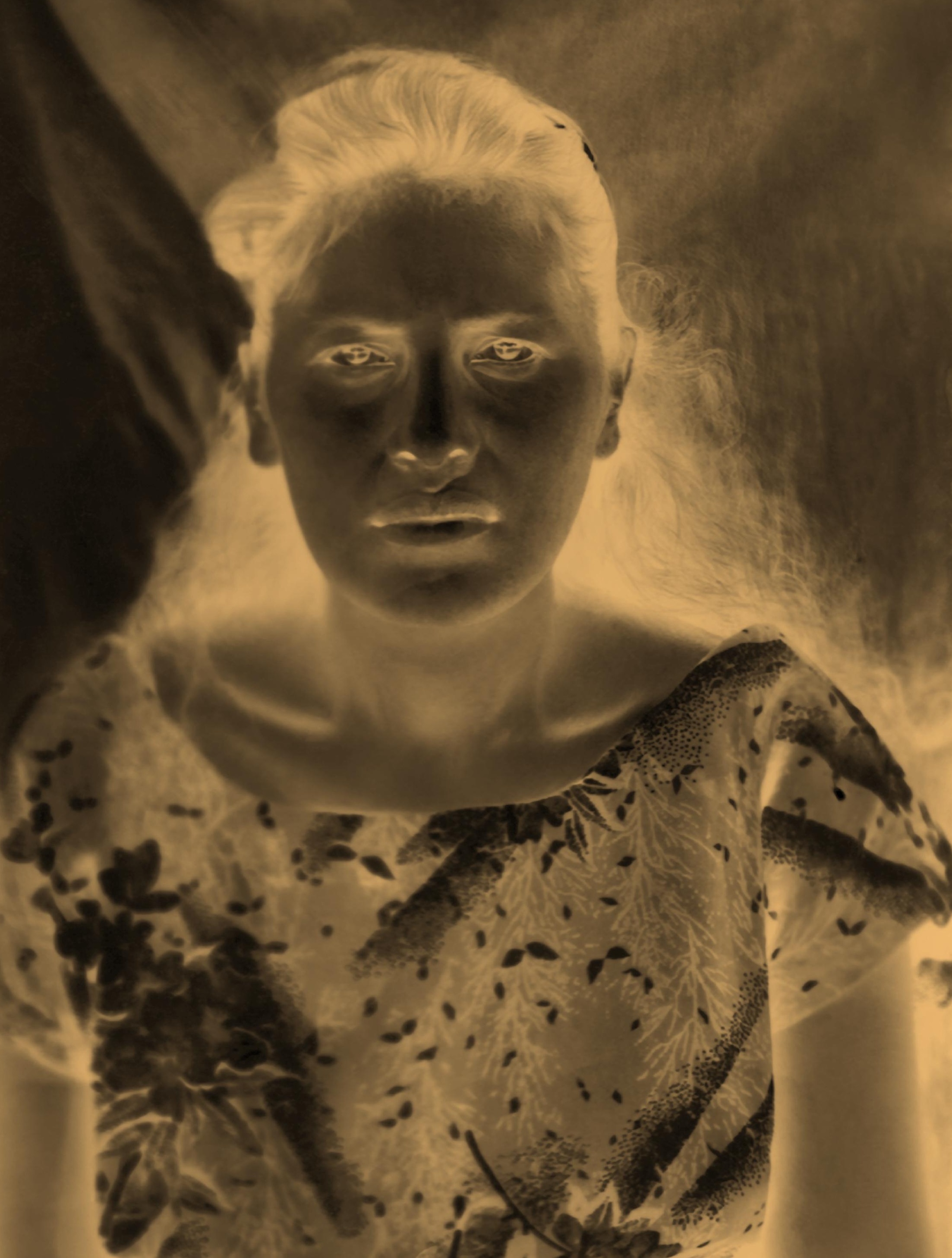


Fotografía latinoamericana contemporánea: imaginarios, archivos y memoria.

Una aproximación a la obra de Milagros De la Torre

\title{
Resumen
}

En el presente ensayo nos proponemos realizar una lectura de la obra "Bajo el sol negro" (19911993) de la peruana Milagros De la Torre, donde se presenta un conjunto de retratos en los que la artista resignifica la práctica fotográfica de los minuteros, muy popular en Cuzco a principios del siglo XX. Nuestro objetivo es considerar cómo, desde el arte contemporáneo, De la Torre produce una obra en la que genera una nueva red de significaciones en torno a la representación de la sociedad peruana. Una serie de fotografías que pueden relacionarse a los conceptos de pureza de sangre, raza, y color de la piel como conjunto estructurador del orden social en la colonia, un orden que continuó luego de la constitución de los Estados Nacionales en América Latina bajo nuevos colonialismos internos.

\section{Palabras claves}

Colonialidad; decolonialidad; fotografía latinoamericana; imaginarios; Milagros De la Torre

\section{Contemporary Latin American photography: imaginaries, archives and memory.}

\section{An approach to the work of Milagros De la Torre}

\begin{abstract}
In this essay we propose to analyze the work "Bajo el sol negro" (1991-1993) by the Peruvian Milagros De la Torre, where a set of portraits is presented to resignify the photographic practice of the minuteros, very popular in Cuzco at the beginning of the 20th century. Our objective is to consider how, from a contemporary art standpoint, De la Torre produces a work where she generates a new network of meanings around the representation of Peruvian society. A series of photographs that can be related to the concepts of purity of blood, race, and skin color as a structuring set of the social order in the colonial era, an order that continued after the constitution of the National States in Latin America under new internal colonialisms.
\end{abstract}

\section{Keywords}

Coloniality; decoloniality; Latin American photography; imaginary; Milagros De la Torre

La photographie latino-américaine contemporaine : imaginaires, archives et mémoire.
Une approche au travail de Milagros De la Torre

\section{Résumé}

Dans cet essai, nous nous proposons d'analyser l'œuvre « Bajo el sol negro » (1991-1993) de la péruvienne Milagros De la Torre, où est présenté une série de portraits qui resignent la pratique photographique des minuteros, très populaire dans Cuzco au début du 20 ème siècle. Notre objectif est de considérer comment, à partir de l'art contemporain, De la Torre produit une œuvre dans laquelle elle génère un nouveau réseau de significations autour de la représentation de la société péruvienne. Une série de photographies qui peuvent être liées aux concepts de pureté de sang, de race et de couleur de peau comme ensemble structurant de l'ordre social des temps coloniaux, un ordre qui s'est poursuivi après la constitution des États nationaux en Amérique latine sous de nouveaux colonialismes.

\section{Mots clés}

Colonialité ; décolonialité ; photographie latino-américaine ; imaginaire ; Milagros de la Torre 


\section{Resumo}

No presente trabalho nos propomos realizar uma leitura da obra "Bajo el sol negro" (19911993) da artista peruana Milagros De la Torre. Na mesma, se presenta um conjunto de fotos nos quais resignifica a prática fotográfica dos minuteiros, muito popular em Cuzco no começo do século XX. Nosso objetivo é considerar como a partir da arte contemporânea, De la Torre produz uma obra na qual gera uma nova rede de significações em torno da representação da sociedade peruana. Uma série de fotografias que podem se relacionar aos conceitos de pureza de sangue, raça e cor da pele como conjunto estruturador da ordem social na colônia, uma ordem que continuou depois da constituição dos Estados Nacionais na América Latina nos países pós-independentistas, sobre novos colonialismos internos.

\section{Palavras chave}

Colonialidade; decolonialidade; fotografia latino-americana; imaginários; Milagros De la Torre

Ruraskakuna atun llagta Latinoameriana suti unaimanda iuiarispa wakachiska kunata kawachingapa. Milagros de la Torre suti ruraskata kawachingapa

\section{Maillallachiska}

Kai mailla kilkaskapi Munanaku kawachinga, sug ruraskata suti "urapi indi llanallaska" kai watakunapi atun waranga iskun iskunsug watapi chasallata atun waranga iskun iskun chunga kimsa luatapi ruraska kai warmi Milagros de la Torre suti chasallata munaku ruraikuna kawachinga cuzco sutipi ñami, tukuikuna iachankuna kawachiku imasami ka iawar, kausai, imas rigcham kanchi. Kunauramanda kausai man kanchu ñugpasina atun llagta America Latina urapi sug kausaikunaapachinaku.

\section{Rimangapa Ministidukuna}

Kausaikuna; sug ruraikuna kallariska; ruraikuna; pangapi ruraska; warmi chasa suti 


\section{Introducción}

En el presente trabajo se analizará la obra Bajo el sol negro (1991-1993) de la artista peruana Milagros De la Torre. Esta obra agrupa una serie de retratos en los que se resignifica la práctica fotográfica de los minuteros, muy popular en Cuzco hacia fines del siglo XIX y principios del siglo XX. Dicha práctica consistía en un revelado a partir de la utilización de mercurio-cromo rojizo, que producía un oscurecimiento del negativo y en su pasaje al positivo un blanqueamiento más profundo de las superficies, dando un efecto de rostros más claros. En Bajo el sol negro, la artista hace uso de esta misma técnica, pero interrumpe el proceso y los retratos son copiados como negativos, dejando al descubierto la máscara roja.

Nos proponemos indagar sobre cómo en esta obra se produce una visión crítica sobre el rol de la fotografía en la representación racial, generando visualidades e imaginarios hegemónicos sobre los cuerpos y las subjetividades. Así, consideramos que esta obra puede relacionarse con los conceptos de pureza de sangre, raza, y color de la piel como conjunto estructurador del orden social en la colonia. Un orden que continuó luego de la constitución de los Estados Nacionales en América Latina en los países postindependentistas, bajo nuevos colonialismos internos.

La propuesta de lectura pone en juego herramientas teórico-metodológicas del 'Giro Decolonial' ${ }^{1}$ que nos permiten analizar esta serie fotográfica como una práctica artística que busca una descolonización de las imágenes-archivo. Es decir, imágenes disparadoras de múltiples imaginarios e iconicidades subyacentes en las que persisten "improntas del pasado colonial" (Catelli, 2014). En la primera parte del este artículo revisaremos ciertas cuestiones claves sobre algunas prácticas representacionales en América Latina destinadas a clasificar a la población; identificando a los indígenas, afrodescendientes y mestizos, como 'tipos' humanos. En la segunda parte nos centraremos en el análisis de Bajo el sol negro y su modo de resignificar dichas prácticas representacionales.

1 El Giro Decolonial se desarrolló en América Latina por el colectivo Modernidad/Colonialidad, integrado por académicos como Aníbal Quijano, Walter Mignolo, Zulma Palermo, Mabel Moraña, Santiago Castro-Gómez, Enrique Dussel, Arturo Escobar, Fernando Coronil, Catherine Walsh, Ramón Grosfoguel, entre otros. El grupo Modernidad/Colonialidad profundiza en el estudio de las herencias coloniales en América Latina y las persistencias de la colonialidad en la contemporaneidad. En otras palabras, busca desmantelar las estrategias epistémicas de la colonialidad.

\section{Construir la Nación, identificar al otro}

Cuando se habla del desarrollo de la fotografía en América Latina durante el siglo XIX y principios del XX suele hacerse referencia a los fotógrafos (tanto extranjeros como locales) que utilizaban el medio fotográfico con un afán de documentar nuestros territorios, y creaban álbumes, postales y archivos fotográficos. Con ello se buscaba crear un 'mapa visual' en relación con los procesos de modernización y progreso: reflejados en ciudades, campos, costumbres, paisajes, tipos populares, indígenas, negros, personajes de la cultura y la política, etcétera. Lo que se veía evidenciado en dichas producciones era el afán de los recientes Estados Nacionales de producir un imaginario ${ }^{2}$ nacional que actuara como fuente de identificación para la sociedad. Un punto de reflexión que puso en el centro del debate la heterogeneidad de las poblaciones de las nuevas naciones (compuestas principalmente por europeos, criollos, indígenas, africanos y la mezcla de dichos grupos) (Solorzano-Thompson y Rivera-Garza, 2009).

En esta búsqueda de construcción identitaria en las naciones postindependentistas, fue cobrando mayor relevancia el 'problema del indio' como ajenidad al proyecto cultural de modernización. Esto llevaba a la definición de políticas sanitarias de control y reorganización de la población indígena, y a incentivar la inmigración de europeos blancos para mejorar la composición racial en el proyecto civilizatorio.

También, hacia fines del siglo XIX la expansión económica, la inmigración, el crecimiento urbano y el incremento de la alfabetización, planteaban nuevos interrogantes y perspectivas en la definición de lo nacional (Masotta, 2005). En dicho contexto, la imagen fotográfica amplía su circulación y consumo a partir de las tarjetas postales, las carte-de-visite y las revistas ilustradas. Y, el retrato fotográfico sirvió para representar simbólicamente los ideales sociales. De esta manera, en los distintos países latinoamericanos fueron surgiendo series fotográficas que iban poniendo el acento en la clasificación e identificación de 'tipos populares', 'tipos indígenas', 'tipos negros'; en oposición al proyecto modernizador que se veía reflejado en las imágenes de las principales ciudades.

\footnotetext{
2 Para la categoría de lo imaginario tomo como base el sentido que le atribuye Castoriadis (2013): una relación entre el simbolismo institucional y la vida social que se desplaza a través de un conjunto de prácticas y espacios interrelacionados, creadores de sentido. Esto es, significaciones esencialmente imaginarias, $-\mathrm{y}$ no racionales, funcionales o reflejos de la realidad-que son particulares de cada sociedad.
} 
Los indígenas y los afrodescendientes pasaron a ser sujetos de representación, cuya imagen servía tanto a estudios de ciencias naturales, etnografía y antropología ${ }^{3}$, como a la documentación y la comercialización de postales y álbumes que coleccionaban los sectores en ascenso (Navarrete, 2017).

Con relación a esto, Mariana Giordano (2012) habla sobre las fotografías de los pueblos originarios y los afrodescendientes (creadas por científicos, funcionarios del estado, fotógrafos, viajeros, exploradores, etcétera) en el período que va desde las últimas décadas del siglo XIX y las primeras del XX. Sobre estas, la autora explica que pueden tomarse como un testimonio de los modos en que visualmente se constituyó una alteridad apoyada en intereses, conceptos y preceptos que conformaban un imaginario sobre el 'otro'. Dichas imágenes se componían a partir de determinados rasgos iconográficos que permitían la conformación de una alteridad. Así, deben ser leídas, según la autora, como informantes de los productores de las imágenes más que de los sujetos representados, puesto que proceden de una relación asimétrica entre el retratado y el fotógrafo.

Esta relación asimétrica es caracterizada por Alex Schlenker a partir de lo que denomina como 'zonas de acción visual' divididas en dos lugares excluyentes por el dispositivo de la mirada (la cámara): el tras-cámara (la zona del ser de quien mira) y el pro-cámara (la zona del no ser de quien es mirado). A partir de lo cual afirma que la fotografía surge a partir de una 'vectorialidad' entre sujeto retratante y objeto retratado: "quien toma la foto difícilmente será el retratado [...]" (Schlenker, 2012, p. 183).

Esta búsqueda de definir al 'otro' ha sido una constante en el pensamiento occidental, el otro refiere a un significante que designa una cultura (étnica, religiosa, etcétera) ajena, extraña, diferente, a la que nunca se podrá comprender plenamente, que siempre mantendrá componentes irreductibles e inclasificables. En

$3 \quad$ Nos referimos a las prácticas biológicas y antropológicas positivistas de fines del siglo XIX y principios del XX en las que se utilizaban herramientas de medición (craneología y frenología) para la clasificación cultural y racial (basándose en la diversidad física). En este contexto, la fotografía ocupó un rol importante en el registro y retrato de los sujetos. Dichas imágenes se componían a partir de ciertos rasgos estilísticos que respondían a convenciones etnográficas y antropométricas: fotografías de frente y de perfil; retratos de cuerpo entero, con descripciones físicas como las medidas (fotografía métrica), los tonos de la piel, etc. Con estas imágenes se intentaba demostrar la existencia de tipos raciales a cuya anatomía distintiva se le asociaban diferencias de carácter y moralidad (Rigat, 2018). otras palabras, una inarticulable e inacabada diferencia (Szurmuk y Mckee Irgwin, 2009).

A estas diferencias les corresponden regímenes visuales canonizados por la modernidad eurocentrada, con los cuales otras culturas han sido racializadas y jerarquizadas por el proyecto modernidad/colonialidad. Este dio lugar a lo que Joaquín Barriendos denomina "el problema de la colonialidad del ver", esto es: "la matriz de colonialidad que subyace a todo régimen visual, basado en la polarización e inferiorización entre el sujeto que observa y su objeto (sujeto) observado" (Barriendos, 2011, p. 15).

Las fotografías de 'tipos' (indígenas, negros) sirvieron no tanto como retratos sino como medios para definir la categoría de 'indio'. Además, en ellas se condensan elementos que la sociedad blanca representaba a través de las imágenes: indumentaria, ambiente y temperamento. Así, se trataba de fotografías creadas estilísticamente para la mirada occidental, a través de la composición, las poses, los vestuarios, y los elementos puestos en juego en la escena. Y, aunque no siempre dichos elementos eran auténticos o propios del sujeto o la comunidad, ayudaban a crear una atmósfera étnica (Trevisan y Massa, 2009). Dichas fotografías en su época fueron consideradas como portadoras de datos objetivos que aportaban al conocimiento antropológico. Hoy pueden ser leídas como huellas de las creencias, actitudes, sentimientos, e imaginarios raciales sobre estos grupos humanos. Con relación a esto Kingman, señala:

En el siglo XIX y en las primeras décadas del siglo $X X$ se profundizarán los conflictos entre la cultura ciudadana y el mundo indígena. No solo se trataba de una disputa por las tierras, el agua, los recursos o la utilización de la fuerza de trabajo, sino de una lucha que se libraba en el campo de lo imaginario: que tenía que ver tanto con acciones cotidianas de violencia simbólica como con la definición de valores y sistemas de representación (Kingman, 2008, p. 347).

En este contexto, principalmente en la primera mitad del siglo $X X$, en distintos países latinoamericanos cobró popularidad la fotografía de minuteros. Esta técnica fotográfica permitía entregar a los transeúntes sus retratos a bajo costo y en pocos minutos. La práctica fue retomada hacia fines del siglo XX por la artista peruana Milagros de la Torre en su obra Bajo el sol negro, en la que propone una reflexión crítica sobre la representación racial y etnográfica. 

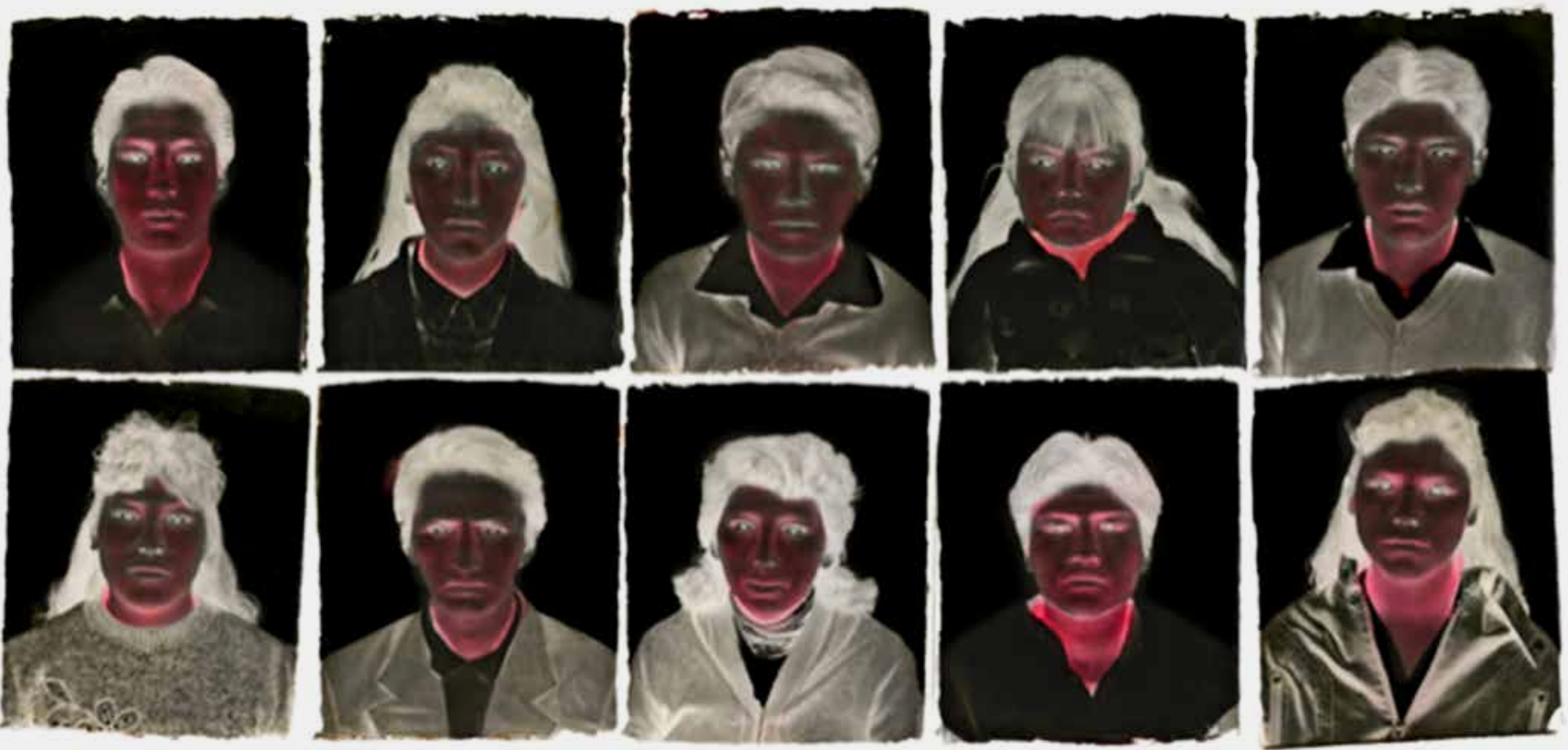

Imagen 1. Under the Black Sun. (De la Torre, 1991).

\section{Bajo el sol negro de Milagros De la Torre}

A comienzos de la década de 1990 la fotógrafa peruana Milagro De la Torre ${ }^{4}$ realiza Bajo el sol negro, una serie de retratos fotográficos de pequeño formato, creados en la ciudad de Cuzco, con la colaboración de transeúntes que se prestaban a ser retratados. Algunos de ellos son retratos grupales y otros reproducen el formato de la foto-carné y las fotografías de identificación policial: rostros de frente y perfil sobre un fondo neutro, con encuadre centralizado hasta los hombros. Con estas fotografías retoma y resignifica una práctica popular en Cuzco a fines del siglo XIX y principios del siglo XX: la fotografía de minuteros.

Los fotógrafos minuteros ofrecían fotografías analógicas generadas a partir de una economía de recursos que les permitía entregar retratos en pocos minutos a

$4 \quad$ Milagros De la Torre nació en 1965, en Lima (Perú). Estudió
comunicación en la Universidad de Lima y fotografía en el London
College of Printing. Se dedica a la fotografía desde 1991 y recien-
temente ha recibido la beca Guggenheim. Su obra forma parte de
colecciones permanentes institucionales en Estados Unidos, Europa
y Latinoamérica, tales como The Art Institute of Chicago; Museum of
Fine Art de Houston; Harvard Art Museum; Museo Nacional Centro de
Arte Reina Sofía; Museo de Arte de Lima; Museo Nacional de Bellas
Artes de Buenos Aires; Museo de Arte Latinoamericano de Buenos
Aires (MALBA) y Museo de Arte Carrillo Gil de la Ciudad de México;
entre otras. Actualmente reside y trabaja en Nueva York. Su obra
completa puede consultarse en el sitio web de la artista:
https://www.milagrosdelatorre.com/

los clientes (de ahí su nombre). Producían tanto fotocarné como retratos grupales en espacios públicos. Los minuteros utilizaban una cámara oscura casera, papel fotosensible y una emulsión de revelado a base de mercurio-cromo rojizo. Por esto, el proceso de producción de la imagen implicaba: una toma directa, a partir de la cual se obtenía un negativo de la imagen; en segundo lugar, la aplicación de la emulsión rojiza para detener la acción de la luz y así preservar la imagen; una instancia de revelado del negativo; y por último, una nueva toma del negativo con la cámara oscura a partir del cual se genera el positivo de la imagen, que constituía el producto final de los fotógrafos minuteros.

Milagros de la Torre detecta que a partir de este particular proceso de revelado a base de mercurio-cromo rojizo se produce un efecto de 'emblanquecimiento'. Sobre ello relata:

Lo extraño era que la persona fotografiada en la fotografía salía [...] con un mejoramiento racial, es decir, la piel del fotografiado se mostraba aristocráticamente más blanca de lo que era, y esto los clientes lo tomaban como parte del oficio del fotógrafo [...] había ahí toda una serie de problemáticas que me di cuenta sucedían casi automáticamente, y todo el mundo lo tomaba por hecho (Sosa et al., 2015). 


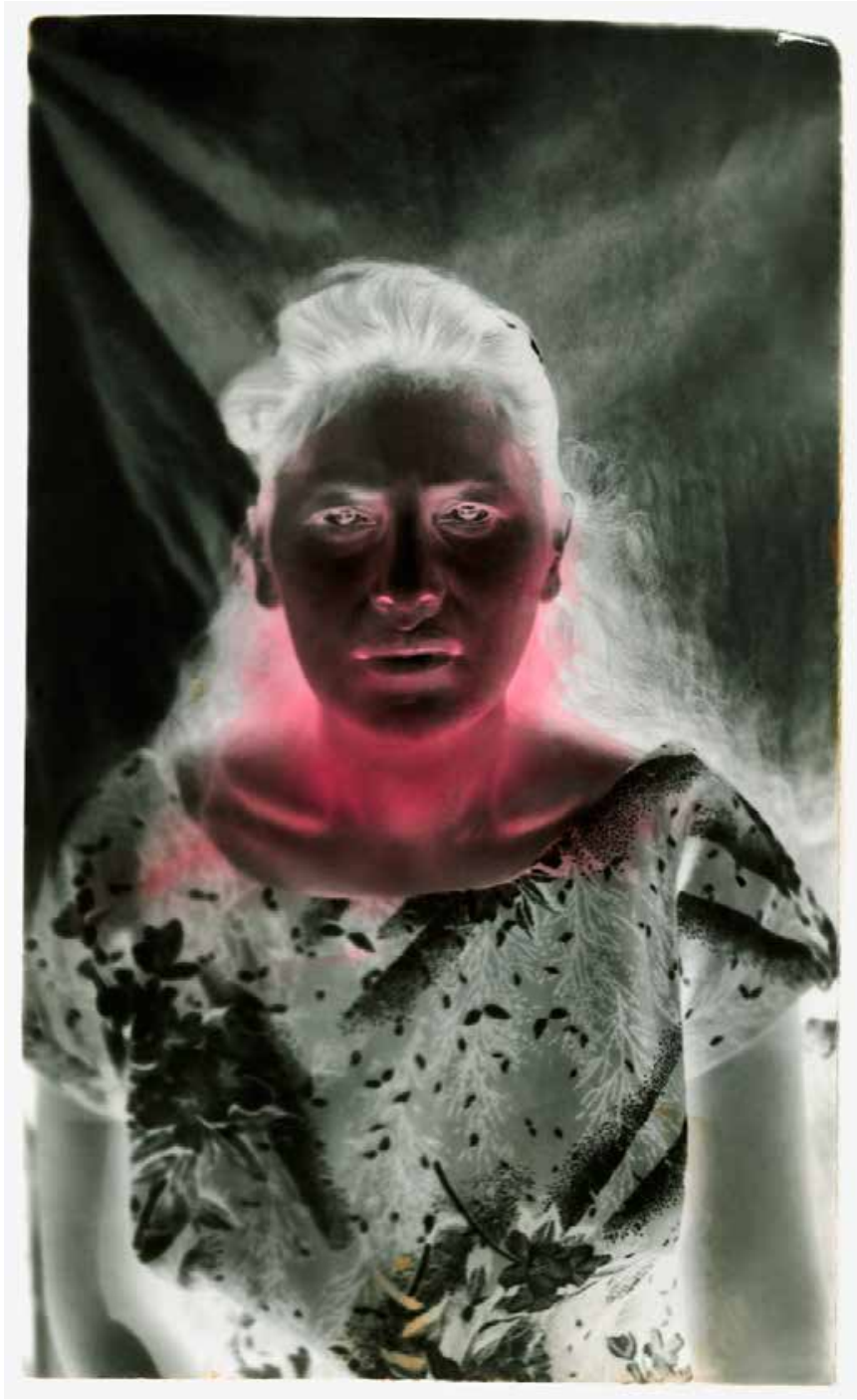

A partir de ello, en Bajo el sol negro, la artista hace uso de la misma técnica, pero en este caso las fotografías son copiadas como negativos, es decir no pasan al positivo. Con esta operación de truncar la etapa final de la práctica de los minuteros y exponer el negativo intervenido con la emulsión rojiza, De la Torre propone visibilizar esta intervención de la imagen que genera un 'aclaramiento' de la piel, para dejar al descubierto el artilugio técnico del emblanquecimiento. La imagen en negativo pasa a ser la forma final de la obra, la película rojiza (invisibilizada por el re-fotografiado del negativo en la práctica de los minuteros) queda expuesta como máscara, sugiriendo las operaciones que contribuían a naturalizar ciertos vestigios coloniales de violencia racial y social a través de un 'inocente' retoque que produce un 'efecto de blancura'.

Recordemos que hacia principios del siglo XX la fotografía era valorada por sus cualidades técnicas y por las posibilidades de ofrecer una imagen directa de lo real (la huella del referente) (Peirce, 1987). En la práctica de los minuteros, más allá de la intervención 'inadvertida' al servicio de un revelado instantáneo, el resultado era una transformación de lo real. Presentando rostros más blancos, resultado que no era cuestionado por los clientes fotografiados. Una práctica naturalizada y generadora de una visualidad sobre los retratados: sujetos más blancos. Esto nos habla de un cierto tipo de construcción de la identidad a partir de negar el propio color de la piel, haciéndolo pasar por un asunto técnico.

Desde esta perspectiva, es importante pensar en cómo la imagen fotográfica, nacida como dispositivo visual de la modernidad, permitió legitimar determinadas formas de representación del otro (no-europeo, no-blanco). Con relación a esto, Christian León afirma:

Al mismo tiempo que el realismo fotográfico, asociado a los dispositivos de captura de la imagen, se convierte en un principio epistemológico de producción de verdad, la racialización de la 
diferencia se transforma en una realidad natural incontrovertible que tiene su demostración en el registro visual. La diferencia cultural empieza a ser capturada, conocida y administrada a través de los vectores de luz de los regímenes escópicos que tramitan la significación, el deseo y el control de la otredad. (León, 2012, p. 120).

De manera similar, Alex Schlenker explica que la fotografía - como dispositivo tecnológico y de la mirada nacida en la modernidad-adquirió la capacidad de operar las cuatro instancias del naturalismo: recolectar (atrapar, cazar, arrancar), clasificar, nombrar, guardar, almacenar y archivar.

Uno de los pilares de la modernidad, "el desarrollo científico y tecnológico como forma de progreso", naturalizó la idea, según la cual, los dispositivos de la mirada - la pintura y la fotografía inicialmente, el cine y el video posteriormente- "solamente" reproducen la realidad tal cual como esta es. Tal presunción de objetividad realista desconoce y niega todo control político de las distintas subjetividades involucradas, convirtiendo a la imagen-mirada y sus dispositivos en un universal de verdad realista. (Schlenker, 2012, p. 177).

En este sentido, Milagros de la Torre, al revelar el artificio sobre el cual se sustentaban aquellas imágenes, subvierte el sentido, generando un juego entre la idea 'positivo-negativo'. Las manchas rojas de mercurio-cromo rojizo expuesta sobre los rostros de los retratados connotan el imaginario dicotómico que caracterizó el sistema social de la colonia: lo blanco como ideal de virtud, pureza, belleza y limpieza. Por el contrario, lo negro como sinónimo de ilegitimidad y desconfianza, donde en el medio de esta dicotomía se situarán las posibles mezclas que darán cuenta de la gran diversidad de sujetos que emergerán en el Nuevo Mundo: los 'mestizos'. Una categoría de clasificación sociocultural que en su origen buscaba generalizar un tipo de mezcla en la América hispánica durante el período colonial, la del indígena con el europeo, y luego para referirse a los hijos de españoles nacidos en Indias. Es un sistema de clasificación que tiene su origen en la doctrina de 'limpieza de sangre' que operó en la sociedad tardo medieval hispana como una "singular concepción genealógica de la condición sociopolítica" (Stolcke, 2008, p. 2). La limpieza de sangre, como sostiene Verena Stolcke, se refería a la calidad de un sujeto que estaba determinada por no descender de moros, judíos y herejes, o cualquier categoría juzgada por la Inquisición.
Con relación a lo anterior, Max Hering sostiene que entre los siglos XVI y XVIII los imaginarios de pureza de sangre y de raza se articularon, y luego progresivamente se asociaron a las diferencias de color en la piel:

[...] la limpieza de sangre estaba íntimamente conectada con el imaginario de la raza de ese entonces, aunque es importante advertir que la concepción de raza, como categoría jerárquica del orden global, era inexistente en la época. Antes existía otra significación de "raza" que permitía diferenciar y construir argumentos de superioridad e inferioridad en el marco de la comunidad cristiana, dado que el sistema de limpieza de sangre y el imaginario de la raza solamente se aplicaba a los neófitos. Desde mediados del siglo XV, en Castilla, raza significó linaje, así como en las colonias después de la Conquista. (Hering, 2011, p. 458).

Sobre esto último el autor agrega que, en el marco de la doctrina de la limpieza de sangre, el término raza significaba "tener defecto de linaje". Es decir, al tener un "linaje manchado" por el pasado genealógico, se tenían raza (Hering, 2011, p. 458). Este sistema se aplicó en las colonias hispanoamericanas, dando un giro respecto a la doctrina española, la 'impureza de sangre' estaba articulada a los colores de la piel, principalmente a partir de fines del siglo XVII:

La limpieza de sangre en España había sido una cuestión genealógica que no tenía relación con el color de la piel. El pasado genealógico solo era visible mediante la reconstrucción genealógica y dependía de la fama y voz pública. Sin embargo, en América esta categoría se convirtió en algo que se podría denominar como somatización genealógica, en tanto que a través del color de la piel se pretendía rastrear el origen y la calidad de un individuo, convirtiéndose en un posible determinante de las relaciones sociales. (Hering, 2011, p. 459).

Desde esta concepción, el cuerpo pasó a inscribirse en un complejo entramado de significados que regulaban su posición social a partir de su 'calidad' de persona, la cual se determinaba en la articulación del color de la piel, la limpieza de sangre (linaje) y la raza. Así, color, pureza, raza y calidad se configuraron como un entramado de valores sociales a través de los cuales se buscaba encausar el comportamiento de los sujetos coloniales propiciando la blancura y el blanqueamiento como el tipo ideal (Hering, 2011, p. 465). 
Todos estos elementos confluirán en la segunda mitad del siglo XIX en la instalación de la moderna categoría de raza. A partir de la cual lo blanco y puro significaba orden y monopolio del poder, en contraposición a lo negro y lo indígena que representaban la base deshonrada de la pirámide social, y con ello de la explotación socioeconómica para sustentar el poder del blanco. En el Nuevo Mundo, el mestizo y las castas representaban aquellos sectores en vías de ascenso, y por ello se transformaron en grupos que debían ser controlados a partir de su estigmatización como el componente del desorden moral de la sociedad (Hering, 2011, p. 466). Como explica Stolcke:

Los términos que se aplicaron a las nuevas categorías de gentes respondían al intento de crear orden en la sociedad colonial circunscribiéndolas. Sin embargo, el número creciente de individuos mezclados representaba una constante amenaza porque su ilegitimidad hacía su ascendencia peligrosamente dudosa. (Stolcke, 2008, p. 18).

De esta manera, el mestizo aparece como una figura sospechosa, de origen oscuro, en donde el color de la piel es parte de su distintivo. Lo anterior hace operativa la ideología de la pureza de sangre, fabricando así a los mestizos, y diferenciándolos de los españoles a los que se aplica la idea de una genealogía sin anomalías (Stolcke, 2008). Es así como el concepto de pureza de sangre alcanzó rápidamente en el Nuevo Mundo a lo afro y lo indígena, estableciéndolos como elementos impuros y desviados.

Ambas formas de clasificación social, la interpretación moral y religiosa de la pureza de la sangre inicial y su concepción moderna racial posterior, se sustentaban en la base de una identidad sociopolítica atribuida al nacimiento y a la ascendencia genealógica. Una dicotomía que se mantiene con los Estados nacionales junto a categorías como la clase, en donde el ideario del blanqueamiento persiste; transformando a los indígenas, los negros y los mestizos como el componente de 'lo popular'.

Dichas relaciones se establecen bajo nuevos colonialismos internos en las naciones postindependentistas, donde se va diferenciando a un 'otro' a partir de una definición binaria de un 'nosotros' y un 'ellos' que se funda en un imaginario social sobre dichas clasificaciones.
Por esto, cuando hablamos de 'poscolonialismo' en América Latina desde un punto de vista temporal surge el cuestionamiento sobre su aplicabilidad, puesto que los países latinoamericanos en su mayoría lograron su independencia en el siglo XIX. En relación con esto Rabasa nos advierte: "[...] obsérvese que el 'pos' no implica un momento en el que se ha superado el colonialismo sino la toma de conciencia de las continuidades y legados coloniales aun siglos posteriores a las independencias políticas" (Rabasa, 2009, p. 221). En este sentido, afirma que referirse al momento poscolonial en América Latina como aquel en el que surgen los Estados nacionales tras las guerras de independencia, carece de rigor. Pues, más allá de las independencias formales, pueden observarse realidades socioeconómicas y culturales en las que se reproducen estructuras coloniales bajo la consolidación de neocolonialismos internos que sometieron a las poblaciones indígenas y negras a procesos de marginalización y exclusión.

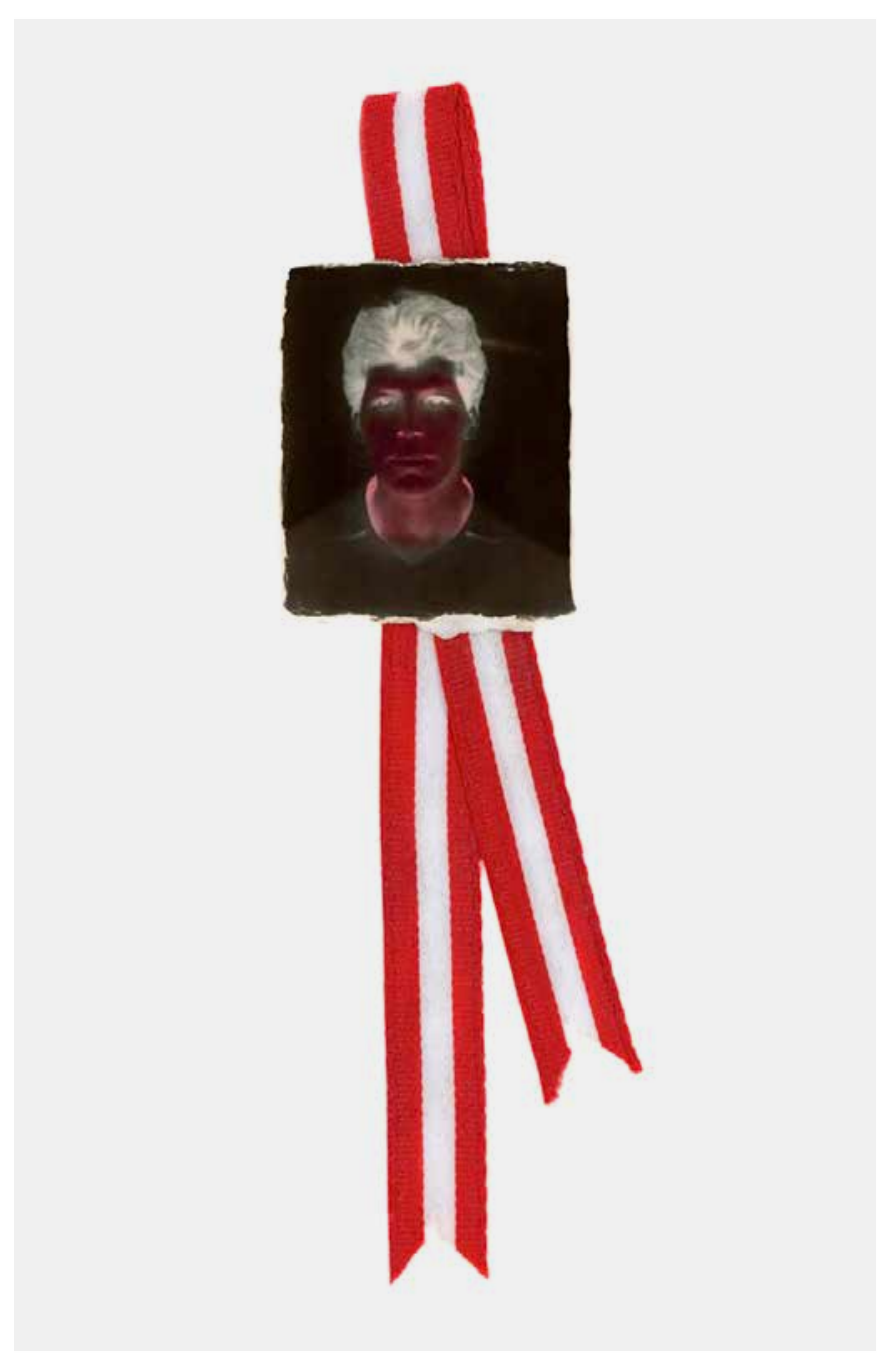

Imagen 3. Bandera. (De la Torre, 1991-1993). 
Esta idea es congruente con la definición de González Casanova sobre el concepto de 'colonialismo interno':

Los Estados de origen colonial e imperialista y sus clases dominantes rehacen y conservan las relaciones coloniales con las minorías y las etnias colonizadas que se encuentran en el interior de sus fronteras políticas. El fenómeno se repite una y otra vez después de la caída de los imperios y de la independencia política de los Estados-nación, con variantes que dependen de la correlación de fuerzas de los antiguos habitantes colonizados y colonizadores en los estados que lograron la independencia. (González Casanova, 2006, p. 416)

En Bajo el sol negro el imaginario social del indígena y del mestizo como estigma, del que hay que desconfiar, queda en la superficie a partir de la interrupción del proceso de revelado y con ello, el blanqueamiento. El rostro queda "tras la mancha roja", dispuesta como máscara. De la Torre nos recuerda de esta manera el imaginario racial que atraviesa nuestra historia, la relación entre el proyecto científico de la Ilustración y el proyecto colonial europeo. Con base en lo anterior, podemos relacionar esta obra y la máscara roja de mercurio-cromo rojizo sobre el rostro de los retratados al modo en que Kant aborda el problema de las razas. Como explica Castro-Gómez (2005), Kant distingue cuatro razas a partir de las distinciones geográficas y el color de la piel: la blanca (Europa), la amarilla (Asia), la negra (África) y la roja (América). Distinción que no solo marcaría las determinaciones externas (a partir del clima y la geografía), sino, además, correspondería a diferencias en cuanto al carácter moral de los pueblos. Es decir, "a diferencias internas marcadas por la capacidad que tienen estos grupos o individuos para superar el determinismo de la naturaleza" (Castro-Gómez, 2005, p. 41). El autor establece así, un orden de jerarquías, en las que destaca a la raza blanca como la mayor perfección de la humanidad.

Podemos entonces pensar está emulsión rojiza expuesta en las imágenes de De la Torre como la simbolización de este componente racial americano negado en el proceso final de las fotografías de los minuteros. El rojo reproduce, a la vez que recuerda, el estereotipo racial-negativo de los indígenas latinoamericanos (la

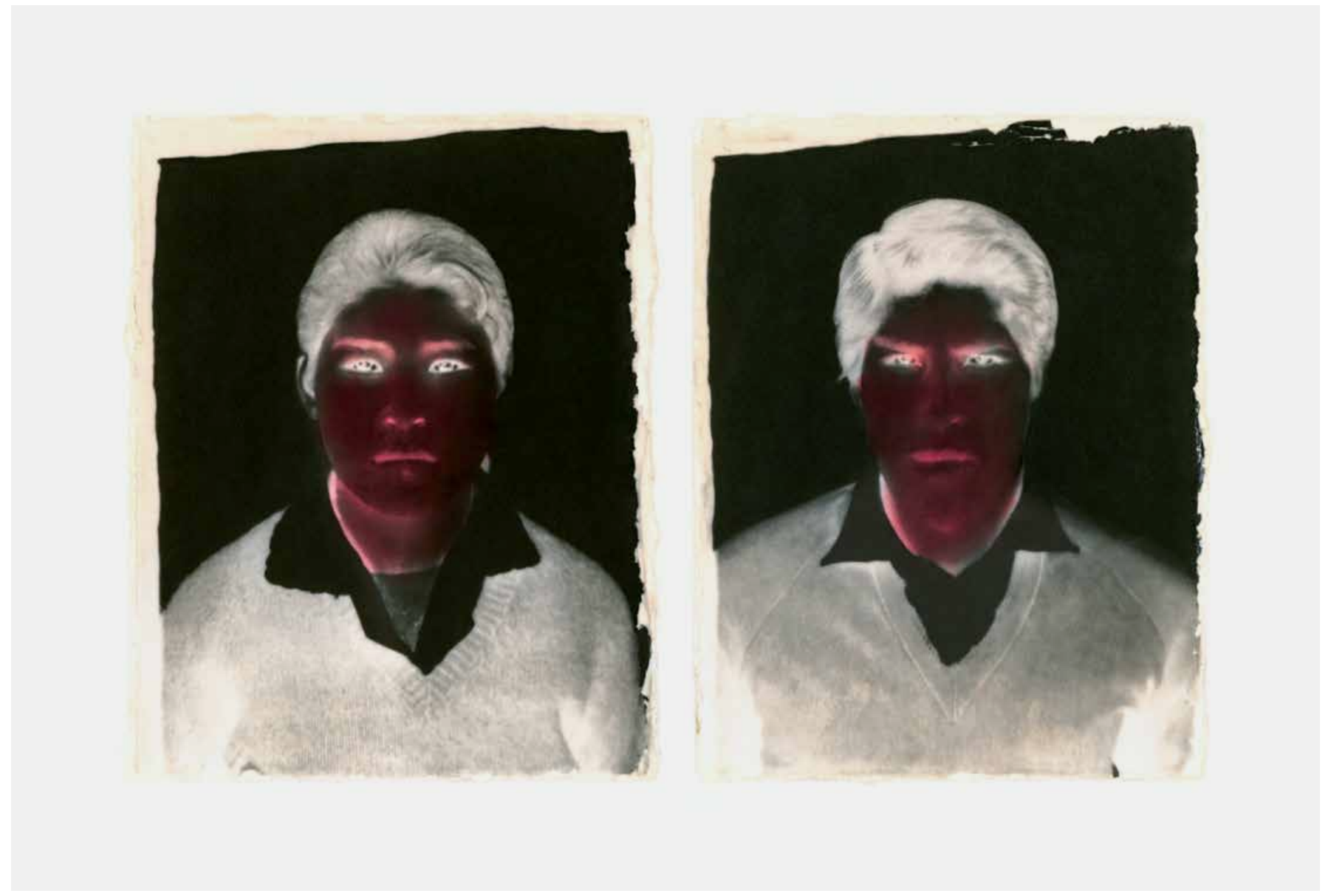

Imagen 4. Díptico, pareja. (De la Torre, 1991-1993). 
raza roja, según Kant). El rojo solo se vislumbra en el negativo de la obra, si la imagen pasa al positivo la piel se vuelve más blanca. También, el rojo remite tanto a la idea de sangre, a la doctrina de limpieza de sangre (y con ella del linaje y la genealogía); como a la idea de raza, a la diferenciación de las razas según los colores de la piel y sus correspondencias morales como rasgos de calidad humana. La mancha roja puede, entonces, pensarse desde la concepción colonial en relación con un linaje manchado.

De la Torre a través de la puesta en escena de un procedimiento que generaba una determinada visualidad, desenmascara un imaginario racial que se halla en la base de la construcción social de las identidades latinoamericanas desde la colonialidad.

Además, ela película roja que recubre los rostros en los retratos remite al mercurio-cromo rojizo que se utilizaba para el revelado de la imagen, pero también se usaba como tópico para desinfectar heridas, quemaduras, excoriaciones y rozadura. ¿Qué heridas se desinfectan en la obra de De la Torre? Una herida que subyace en los problemas de identidad latinoamericana, que atraviesa toda nuestra historia, la constitución social a partir de la matriz colonial del poder, es decir, sujetos clasificados, racializados y jerarquizados por la colonialidad (Mignolo, 2012, p. 43). Este es un proceso que continuó su curso, aun después de las independencias bajo la mácula de nuevos colonialismos internos. Como explica Aníbal Quijano la construcción de las hegemonías en base a la raza (blanca) fue una forma de legitimar la dominación colonial:

En América, la idea de raza fue un modo de otorgar legitimidad a las relaciones de dominación impuestas por la conquista. [...] la expansión del colonialismo europeo sobre el resto del mundo, llevo a la elaboración de la perspectiva eurocéntrica de conocimiento y con ella a la elaboración teórica de la idea de raza como naturalización de esas relaciones coloniales de dominación entre europeos y no-europeos. (Quijano, 2001, p. 203).

En esta obra, la artista, revela la herida colonial, "el sentimiento de inferioridad impuesto a los seres humanos que no encajan en el modelo predeterminado por los relatos euroamericanos" (Mignolo, 2007, p. 17). La herida colonial es consecuencia del discurso racial, una herida que América Latina no ha sanado todavía. Como advierte Mignolo:
La herida colonial, sea física o psicológica, es una consecuencia del racismo, el discurso hegemónico que pone en cuestión la humanidad de todos los que no pertenecen al mismo locus de enunciación (y a la misma geopolítica del conocimiento) de quienes crean los parámetros de clasificación y se otorgan a sí mismos el derecho a clasificar. (Mignolo, 2007, p. 34).

De la Torre interrumpe el proceso de representación de los minuteros, mostrando la máscara, tras la que se oculta el rostro mestizo en una sociedad jerarquizada y clasificada racialmente por la 'matriz colonial' que hizo posible la organización sociohistórica del mundo 'moderno/colonial' (Mignolo, 2008, p. 35), a través del control del ser, del poder, del saber y de la naturaleza.

El título de la obra opone el valor positivo de lo negro, la luz no blanca del sol que refuerza la especificidad de una población con altos porcentajes de indígenas, mestizos y negros, rompiendo con ello el canon de lo blanco y lo occidental. Así, el juego positivo-negativo de la obra, propone una crítica a la construcción de alteridad como la afirmación de la identidad de Occidente, en el sentido de que lo no-europeo es todo lo negativo y Occidente lo positivo. Estas son categorías binarias propias de la modernidad, en la que la alteridad se define desde la incapacidad de representarse a sí misma. Así, la representación de los dominados es construida por otros, y posteriormente asumida como identidad. De esta manera, dichas representaciones se naturalizan e instituyen en los imaginarios socioculturales y con ellos en los procesos de producción de subjetividades. Alejandro De Oto y Laura Catelli se refieren a esto último explicando el poder colonial:

Lo que hace el colonialismo, pero deberíamos decir, los colonialismos, es desplegar un poder proliferante que inscribe las formas mismas de las relaciones sociales y las maneras en que los sujetos se representan a sí mismos con respecto al resto. Ese poder proliferante define territorios, delimita espacios y, a la par, constituye una territorialidad y una espacialidad desde la que se enuncia. (De Oto y Catelli, 2018, p. 235).

En la década de los noventa del siglo XX se cumplían los quinientos años del colonialismo español. En este contexto, De la Torre produce esta serie en la que genera una visión crítica sobre una larga tradición de representación de los sujetos no europeos, poniendo de manifiesto la violencia del colonialismo y la influencia de las 
prácticas visuales en la producción de esas alteridades. Desde esta perspectiva es posible pensar la obra de Milagros de la Torre desde herramientas teórico-metodológicas de la decolonialidad de la estética, una perspectiva de análisis que ha cobrado relevancia en las últimas décadas dentro del grupo Modernidad/ Colonialidad.

El Giro Decolonial se presenta como una opción para pensar críticamente las herencias coloniales y desmantelar las estrategias epistémicas de la colonialidad. Es decir, de la dimensión simbólica de la construcción de identidades y subjetividades (Castro-Gómez y Grosfoguel, 2007). Podemos distinguir al 'colonialismo' como proceso y aparatos de dominio político y militares sobre las colonias; la 'colonialidad' como fenómeno histórico más complejo que no termina con el fin del colonialismo, que refiere a un patrón de poder que opera a través de la naturalización de jerarquías territoriales, raciales, culturales y epistémicas. Lo que posibilita la reproducción de las relaciones de dominación (noción que se remonta a la de colonialidad de poder de Quijano). En este sentido, "poner de relieve la estructura y el funcionamiento de este patrón es la tarea del proyecto decolonial [...]" (Mignolo, 2012, p. 37).

Desde esta perspectiva, la colonialidad es constitutiva de la modernidad (Mignolo, 2016). En términos de Enrique Dussel, la modernidad se inicia con la invasión de América por los españoles, dando lugar a la apertura geopolítica de Europa al Atlántico, y al despliegue del 'sistema-mundo' y la invención del sistema colonial que durante años irá beneficiando económica y políticamente a Europa. Todo este proceso, advierte, es simultáneo al desarrollo del capitalismo, es decir, "modernidad, colonialismo, sistema mundo y capitalismo son aspectos de una misma realidad simultánea y mutuamente constituyente" (Dussel, 2005, p. 139).

Por otra parte, Mignolo afirma que la modernidad se fue naturalizando como una retórica global que oculta su lado oscuro: la reproducción de la colonialidad (Mignolo, 2008, p. 2). Además, plantea con ello que un primer desafío de la opción decolonial es el desprendimiento de las epistemologías occidentales que colonizaron los distintos ámbitos de la vida para pensar desde lógicas-otras que den una apertura a la pluralidad de los lugares de enunciación y experiencias de vida. De todas las esferas que componen la matriz colonial del poder, Mignolo advierte que es la epistémica la más importante, puesto que tiene un doble papel, de controlador y de protagonista:
Como protagonista, lo epistémico es parte de la esfera del conocimiento y de la distinción entre conocer y sentir, entre razón y sentimientos, entre racionalidad y estética. Como controlador es en lo epistémico de la cosmología occidental donde todas estas distinciones tienen sentido, y no lo tienen fuera de esta cosmología. Por eso es necesario desprenderse, como insiste Quijano, del eurocentrismo como cuestión epistemológica. (Mignolo, 2012, p. 37).

Una de las dimensiones de este desprendimiento del eurocentrismo es la estética y los distintos dispositivos visuales que, nacidos en la modernidad, sirvieron a generar y administrar las otredades. En este sentido, la estética es otra de las dimensiones constitutivas y constituyentes de la modernidad-colonialidad (Gómez Moreno y Mignolo, 2012). La estética, en términos de Mignolo, es el resultado de la imposición de reglas al sentir, al pensar, al hacer, que trazó Kant en el siglo XVIII sobre la aiesthesis ${ }^{5}$. En base a estas premisas es posible pensar en una descolonización de la visualidad y en prácticas que intentan liberarse de la colonialidad, como advierte Gómez Moreno:

Las estéticas decoloniales son respuestas de sujetos colonizados que crean lugares de enunciación desobedientes a la colonialidad estética del hacer, el pensar y a la regulación estética del gusto. Son interpelaciones y trazados de rutas propias que apuntan hacia horizontes distintos a la calle de dirección única, que es la vía de la modernidad, construida con carne y piedra desde el siglo XVI. (Gómez Moreno, 2015, p. 21).

Este autor explica que las estéticas decoloniales habilitan dos operaciones: 1) hacen visible las diversas formas en las que opera la colonialidad, ya sea en el campo del arte como afuera, y 2) las estéticas decoloniales generan y señalan posibles desprendimientos de los regímenes de la colonialidad estética. Sobre esto concluye:

\footnotetext{
5 Mignolo explica que los significados de la palabra aesthesis, que se origina en el griego antiguo, giran en torno a vocablos como "sensación", "proceso de percepción", "sensación visual", "sensación gustativa" o "sensación auditiva". Además, a partir del siglo XVII, dicho concepto se restringe, y pasa a significar "sensación de lo bello", dando lugar al nacimiento de la estética como teoría, y el concepto de arte como práctica, a partir de Kant. Sobre lo cual afirma: "Esta operación cognitiva constituyó, nada más y nada menos, la colonización de la aesthesis por la estética; puesto que, si aesthesis es un fenómeno común a todos los organismos vivientes con sistema nervioso, la estética es una versión o teoría particular de tales sensaciones relacionadas con la belleza" (Mignolo, 2010, p. 14).
} 


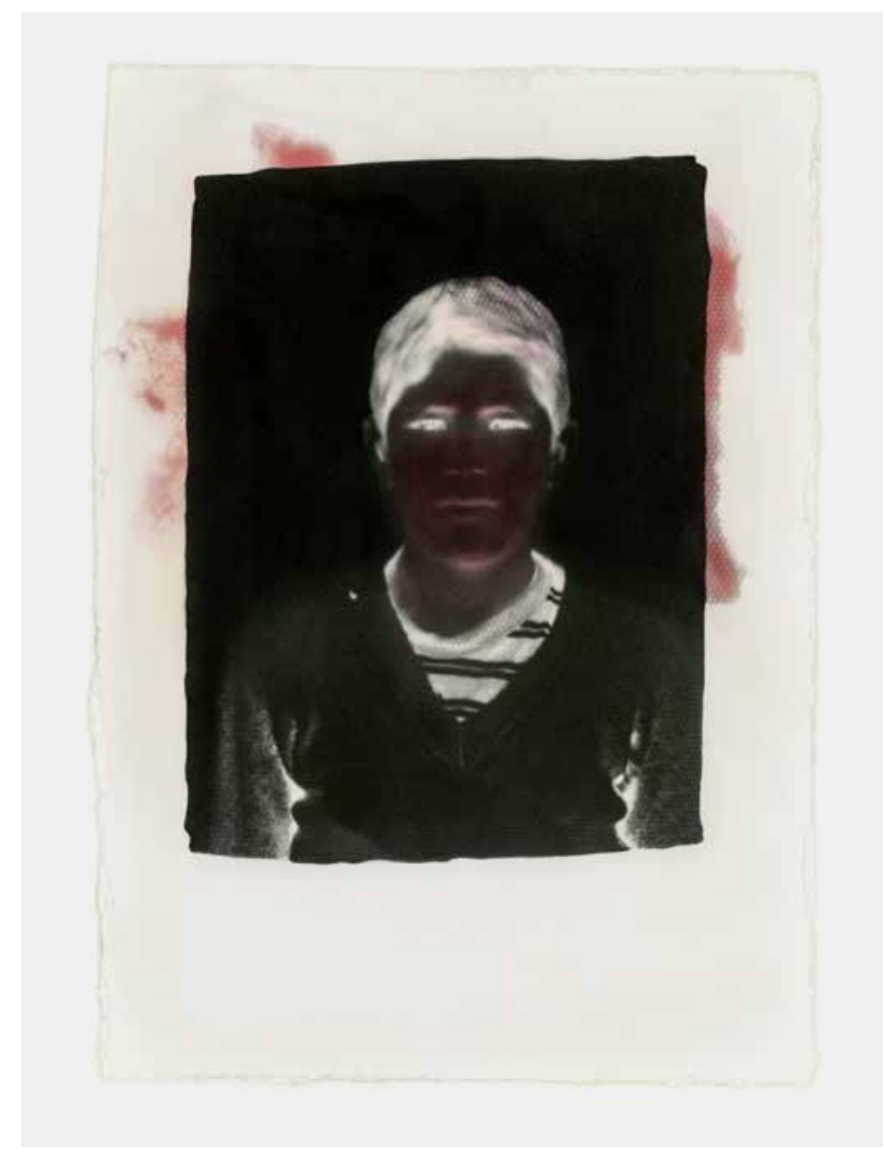

"Las estéticas decoloniales contribuyen a decolonizar la estética para liberar las subjetividades, o para decirlo de otra manera, a descolonizar el ser liberando las subjetividades" (Gómez Moreno, 2015, p. 20-21).

En este sentido es que podemos interrogarnos por prácticas artísticas generadoras de visualidades que buscan descolonizar las imágenes, indagar las relaciones de poder constituyentes de las prácticas de representación y plantear, como afirma Schlenker (2012, p.180), un 'giro-visual-decolonial' donde las imágenes permitan develar la matriz colonial de poder.

Milagros de la Torre desmantela una dimensión estética de la representación de la sociedad peruana, y al hacerlo pone de manifiesto no solo la colonialidad del ver sino también la colonialidad del poder, del saber, del ser y del sentir, que atraviesa a estos sujetos que aceptan un artilugio técnico que genera un blanqueamiento de la piel.

De esta manera, Bajo en sol negro expone la violencia de la representación fotográfica en la práctica de los minuteros, cuyo procedimiento de blanqueamiento esconde la violencia epistémica del pensamiento europeo que busca establecer leyes universales, clasificar,
Imagen 5. Niño. (De la Torre, 1991-1993).

estereotipar y jerarquizar, desde la colonialidad del poder, las formas otras de ser, pensar, sentir, y ver.

\section{Reflexiones finales}

En las últimas décadas es posible identificar el surgimiento en Perú (y podemos extenderlo a Latinoamérica en general) de obras fotográficas que cuestionan la transparencia del registro fotográfico. A través de producciones conceptuales que incorporan diferentes operaciones artísticas (puesta en escena, intervención, montaje, uso y manipulación de archivos, entre otras) propias del arte contemporáneo. La obra creada por De la Torre podemos ubicarla dentro de lo que Andrea Giunta (2014) caracteriza como una práctica común del Arte Latinoamericano Contemporáneo: retomar el pasado para hablar el presente. En el caso de Bajo el sol negro, el pasado es retomado y resignificado para cuestionar las continuidades de la colonialidad en los imaginarios identitarios de América Latina.

En su búsqueda de resignificar una práctica canónica de la fotografía, Milagros de la Torre pone de manifiesto los modos en que las prácticas visuales han participado en la construcción de imaginarios hegemónicos 
de subhumanización de los indígenas. Allí es posible observar un 'gesto decolonial' (Lucero, 2019). Es decir, un cuestionamiento a los cánones eurocentrados, y a las injerencias de la colonialidad (Palermo, 2009) en los regímenes visuales basados "en la polarización e inferiorización entre sujeto que observa y su objeto (o sujeto) observado" (Barriendos, 2011, p. 15).

Por último, en la serie fotográfica de esta artista peruana puede advertirse el trazado de un arco temporal en el que se conectan el presente y el pasado y se exploran los regímenes racializados de representación (Hall, 1997) y los procesos de subjetivación, expresando una visión crítica de los "legados de la colonialidad" (Mignolo, 2016). Es decir, de la continuidad y refuncionalización a través de imaginarios y prácticas visuales de ciertas formas del ejercicio de la violencia provenientes del pasado colonial (Catelli, 2014).

En esta búsqueda de descolonizar las imágenes archivo, la artista expone los imaginarios subyacentes en las prácticas visuales y cómo las imágenes técnicas (fotografía y cine) se convirtieron en un principio de producción de diferencias socioculturales. De la Torre abre de esta manera la posibilidad de una descolonización de la mirada y la memoria.

\section{Referencias}

Barriendos, J. (2011). La colonialidad del ver. Hacia un nuevo diálogo visual interepistémico. En Nómadas Regímenes de visualidad emancipación y otredad desde América Latina. 35.13-29. Disponible en: https://tinyurl.com/yhersx59 Consultado el 22/09/2020.

Castoriadis, C. (2013). La institución imaginaria de la sociedad. Buenos Aires: Tusquets.

Castro-Gómez, S. (2005). La hybris del punto cero: ciencia, raza e Ilustración en la Nueva Granada (17501816). Bogotá: Pontificia Universidad Javeriana. En Castro-Gómez, S. y Grosfoguel, R. (eds.) El giro decolonial. Bogotá: Iesco-Pensar-Siglo del Hombre Ed.

Catelli, L. (2014). Improntas coloniales en las prácticas artísticas latinoamericanas: versiones del retrato etnográfico en la Serie 1980-2000 de Luis González Palma. Caiana. 5.14-18. Disponible en: https://tinyurl.com/y2z9zv63

Consultado el 25 de mayo de 2020.
De Oto, A. y Catelli, L. (2018). Sobre colonialismo interno y subjetividad. Notas para un debate. Tabula Rasa. 28. 229-255. Colombia: Universidad Colegio Mayor de Cundinamarca Bogotá. Disponible en: https://tinyurl.com/wryb4n78

Consultado el 25 de mayo de 2020.

Dussel, E. (2005). TransModernidad e interculturalidad (Interpretación desde la Filosofía de la Liberación). (UAM-Iz., México City). Disponible en: https://tinyurl.com/379jy7jz Consultado el 22/09/2020.

Giordano, M. (2012). Indígenas en la Argentina. Fotografías 1860 a 1970. Buenos Aires: El Artenauta.

Giunta, A. (2014). ¿Cuándo empieza el arte contemporáneo? Buenos Aires: Fundación Arte BA.

Gómez Moreno, P. (2015). Estéticas fronterizas: diferencia decolonial y opción estética decolonial. Ecuador: Universidad Distrital Francisco José de Caldas Universidad Andina Simón Bolivar.

Gómez Moreno, P. y Mignolo, W. (2012). Estética y opción decolonial. Bogotá: Distrital Francisco José de Caldas.

González Casanova, P. (2006). Colonialismo interno [una redefinición], en A. Borón, J. Amadero \& S. González. (Eds.). La teoría marxista hoy. 409-434. Buenos Aires: Clacso.

Hall, S. (1997). The Spectacle of the 'Other? Representation. Cultural Representations and signififying Practices. Gran Bretaña: SAGE.

Hering Torres, M. (2011). Color, pureza, raza: la calidad de los sujetos coloniales, en Heraclio Bonilla (Ed.) La cuestión colonial, Bogotá: Universidad Nacional de Colombia.

Kingman Garcés, E. (2008). La ciudad y los otros. Quito 1860-1940. Higienismo, ornato y policía. Quito: Flacsosede Ecuador.

León, C. (2012). Imagen, medios y telecolonialidad: hacia una crítica decolonial de los estudios visuales. Aisthesis. 51. 109-123. Disponible en: https://tinyurl.com/fmee9wfs Consultado el 22/09/2020.

Lucero, M. (2019). Memorias de Brasil y Cuba. Gestos decoloniales, prácticas deministas. Rosario: UNR Ed. 
Masotta, C. (2005). Representaciones e iconografía de dos tipos nacionales. El caso de las postales etnográficas en Argentina 1900-1930., en Mariana Baron Superville (Coord.) Arte y antropología en argentina. Buenos Aires: Fundación Telefónica, Fundación Espigas, Fundación para la Investigación del Arte en Argentina.

Mignolo, W. (2007). La idea de América Latina. La herida colonial y la opción decolonial. Barcelona: Gedisa.

(2016). El lado más oscuro del

Renacimiento. Alfabetización, territorialidad y colonización. Popayán: Universidad del Cauca. (2010). Aiesthesis decolonial. Revista Calle 14. 4(4). 10-25. Disponible en: https://tinyurl.com/uxrd482e Consultado el: 22/09/2020. (2008) “La Opción descolonial", en Revista Letral № 1 año 2008. Universidad de Granada. Disponible en: https://tinyurl.com/6zes4nam Consultado el: 22/09/2020.

(2012) "Primera parte: lo nuevo y lo decolonial", en Gómez, P. y Mignolo, W. (2012) Estética y opción decolonial. Bogotá: Universidad Distrital Francisco José de Caldas.

Navarrete, J. (2017). Escribiendo sobre fotografía en América Latina. Antología de textos 1925-1970. Montevideo: CDF.

Palermo, Z. (Comp.) (2009) Arte y estética en la encrucijada descolonial. Buenos Aires: Ed. del Siglo.

Peirce, C. (1987). La ciencia semiótica. Buenos Aires: Nueva Visión.

Quijano, A. (2001). “Colonialidad del poder, cultura y conocimiento en América Latina", en Walter Mignolo (Ed.) Capitalismo y geopolítica del conocimiento. El eurocentrismo y la filosofía de la liberación en el debate intelectual contemporáneo. Buenos Aires: Ediciones Signo-Duke University Press. pp. 117-132.

Rabasa, J. (2009). "Poscolonialismo" en Mónica Szurmuk y Robert Mckee Irgwin (coords.) Diccionario de Estudios Culturales Latinoamericanos. México: Siglo XXI Editores.
Rigat, L. (2018). La representación de los pueblos originarios en la fotografía latinoamericana contemporánea: de la imagen de identificación a la imagen de reconocimiento.: Montevideo: CDF.

Schlenker, A. (2012). Imagen, memoria, modernidad: "perspectivas-otras" para el abordaje de la representación visual, en Gómez, P. y Mignolo, W. (2012) Estética y opción decolonial. Bogotá: Universidad Distrital Francisco José de Caldas.

Solorzano-Thompson, N. y Rivera-Garza, C. (2009). "Identidad" en Mónica Szurmuk y Robert Mckee Irgwin (coords.) Diccionario de Estudios Culturales Latinoamericanos. México: Siglo XXI Editores.

Sosa, D., Gutierrez, M., La Rosa, P., y Landro, F. (2015). Fotografía en profundidad Milagros de la Torre. El Ciclo. Disponible en: https://tinyurl.com/ft66nmtp

Stolcke, V. (2008). Los mestizos no nacen sino que se hacen, en Verena Stolcke y Alexandre Coello (eds.). Identidades Ambivalentes en América Latina (Siglos XVI-XXI), Barcelona: Bellaterra.

Szurmuk, M. y Mckee Irgwin, R. (coords.) (2009). Diccionario de Estudios Culturales Latinoamericanos. México: Siglo XXI Editores.

Trevisan, P. y Massa, L. (2009). Fotografías cusqueñas atravesando el indigenismo, Revista Aisthesis. 46. 39-64. Disponible en: https://tinyurl.com/kdk43puw 5yxc6kft Consultado el 25/05/ 2020. 